\title{
Influence of different cell disruption techniques on mono digestion of algal
} biomass

\author{
Sebastian Schwede ${ }^{1, *}$, Alexandra Kowalczyk ${ }^{1}$, Mandy Gerber ${ }^{1}$, Roland Span ${ }^{1}$ \\ ${ }^{1}$ Ruhr-Universität Bochum, Thermodynamics, Bochum, Germany \\ * Corresponding author. Tel: +49 23432 26390, Fax: +49 23432 14163, E-mail:s.schwede@thermo.rub.de
}

\begin{abstract}
Due to high growth rates microalgae provide an enormous potential as a source for biomass besides conventional energy crops. The algal biomass can be used for bioenergy production. Anaerobic digestion to biogas is one of the most energy-efficient and environmentally beneficial technologies for alternative energy carrier production. The resistance of the algal cell wall is generally a limiting factor for cell digestibility. In the present work different cell disruption techniques (microwave heating; heating for 8 hours at $100^{\circ} \mathrm{C}$; freezing over night at $-15^{\circ} \mathrm{C}$; French press; ultrasonic) on algal biomass of Nannochloropis salina were carried out. The disrupted material was digested to biogas in batch experiments according to VDI 4630. The results indicate that hydrolysis of algal cells is the rate-limiting step in anaerobic digestion of algal biomass. Cell disruption by heating, microwave and French press show a considerable increase in specific biogas production and degradation rate. Compared to the untreated sample the specific biogas production was increased for the heating approach by $58 \%$, for the microwave by $40 \%$ and for the French press by $33 \%$.
\end{abstract}

Keywords: Anaerobic digestion, Microalgae, Cell disruption, Specific biogas production, Pretreatment

\section{Introduction}

Microalgae are microscopic algae and cyanobacteria, which use sunlight and atmospheric carbon dioxide for growth by photosynthesis. The common doubling time is 3.5 to 24 hours in the exponential growth phase [1]. Compared to terrestrial plants with biomass production rates of 20 to 25 tons per ha and year, production rates of more than 100 tons per ha and year have been obtained for microalgae in photobioreactors or in high-rate raceway ponds [2]. Besides the reduction of carbon dioxide emission by using algae as source for biofuels, the production of algal biomass is not competing with conventional agriculture for resources [3], [4].

Anaerobic digestion of biomass to produce biogas is, concerning the multiple utilization, a promising technology for bioenergy production [5]. The fermentation process of organic matter is divided into four steps conducted by different consortia of microorganisms and leads to a gas, which mostly consists of methane and carbon dioxide. The rate of organic degradation depends on the particle size and the access of the microorganisms to the particular components of the substrate at hydrolysis step. For substrates with high amounts of complex biopolymers like lipids, cellulose and proteins the hydrolysis is the rate-limiting step. For easily biodegradable material like dissolved carbohydrates (e.g. glucose) methanogenesis and acetogenesis are rate-limiting due to lower growth rates of the involved bacteria. Algal biomass contains high amounts of lipids and proteins and the resistance of the cell wall is one of the limiting factors for cell digestibility [6]. Many green microalgae possess a thin trilaminar outer wall (TLS) with a very high resistance to chemical and enzymatic degradation based on the incorporation of insoluble, non-hydrolysable aliphatic biomacromolecules called algeanans [7, 8]. For Nannochloropsis salina (N.salina), a unicellular marine eustigmatophyceae, $1-2 \%$ of dry matter was detected as algeanans [8].

Aim of the current work was to show one of the two bottlenecks of N.salina biomass as mono-substrate in anaerobic digestion processes: the resistance of algal cell walls to 
enzymatic hydrolysis beside the unbalanced chemical composition due to low C/N-ratio. Batch experiments of physically disrupted cell material were carried out in comparison to untreated algal cells.

\section{Methodology}

\subsection{Substrate}

As substrate for the batch tests algal biomass from N.salina was used. Algal biomass was taken from Phytolutions Ltd., Bremen. Algal sludge was harvested by centrifugation to dry matter content of $35 \mathrm{wt} \%$. For disruption the algal biomass was suspended in tap water. The content of total solids (TS) and volatile solids (VS) before and after digestion was determined according to DIN 12879 and DIN 12880 [9, 10].

\subsection{Cell disruption}

Cell disruption of algal biomass was performed by different physical methods. Experimental conditions were optimized according to different sources (e.g. protein purification, lipid extraction), since less data for pretreatment of algae in biogas fermentation is available [1114]. The influence of temperature was examined by freezing over night at $-15^{\circ} \mathrm{C}$, heating for 8 hours at $100^{\circ} \mathrm{C}$ in a compartment dryer (Function line, Heraeus) and by microwave heating (five times until boiling at $600 \mathrm{~W}$ and $2450 \mathrm{MHz}$; Inverter Grill, Panasonic). For ultrasonic treatment the cell suspension was disrupted three times for 45 seconds at $200 \mathrm{~W}$ with $30 \mathrm{kHz}$ output (Sonifier 250, Branson). Influence of high pressure homogenization was examined by French press (French pressure cell press, TermoSpectronic). Two runs at $10 \mathrm{MPa}$ were conducted for each sample.

To validate the disruption success the absorption of centrifuged samples ( $3 \mathrm{~min}$ at $13400 \mathrm{rpm}$; dilution $1 / 10$ ) were photometrically measured. The three aromatic amino acids phenylalanine, tyrosine and thyptophan show maximal absorption at $280 \mathrm{~nm}$. These values correlate with the amount of released protein.

\subsection{Anaerobic digestion experiments}

Anaerobic digestion of $N$. salina was carried out as batch tests according to VDI 4630 [15]. Digestate from a biogas plant (input material maize silage and cattle dung) was taken as inoculum in a ratio of $2 / 1$ compared to the substrate. $7 \mathrm{~g}$ VS were appointed from the digestate, $3.5 \mathrm{~g}$ VS from the algal biomass. The difference to $400 \mathrm{ml}$ (sample volume) was filled up with tap water. In addition the inoculum was mono-digested. All approaches were investigated in triplicate batch tests at $38^{\circ} \mathrm{C}$ about a period of 40 days. The produced biogas volume was recorded by measurement of the displacement of a seal liquid (55.2 g/l sulphuric acid; $200 \mathrm{~g} / \mathrm{l}$ sodium sulphate decahydrate) in $400 \mathrm{ml}$ eudiometers. Dry gas volumes were corrected to standard temperature and pressure conditions (STP: $0^{\circ} \mathrm{C}, 1013 \mathrm{hPa}$ ).For calculation of the biogas volume produced by the algal biomass, the inoculum gas volume was deducted.

\subsection{Regression equation}

An equation (Eq. (1)) was fitted to every sample to illustrate the daily gas production over retention time.

$$
V_{S T P, d r}(t)=a+\frac{b}{2} \cdot(\tanh (c \cdot(t-d))+1)+\frac{e}{2} \cdot(\tanh (f \cdot(t-g))+1)
$$


where $V_{S T P, d r}$ is the dry biogas volume under standard temperature and pressure conditions, $t$ is the time and $a$ to $g$ are fitting parameters used to describe the progression. Eq. (1) was used to combine the triplicate approaches and to deduct the gas production of the inoculum.

\section{Results}

All exerted disruption techniques were successful and showed higher absorption compared to the untreated sample (Figure 1). Photometrical measurement due to released cytosolic protein by cell wall deletion was highest in French press treated samples (2.18). Decreasing amounts were detected in high temperature (1.74) and microwave (1.3) samples. Cell disruption in ultrasonic (0.79) and frozen (0.31) samples was less successful.

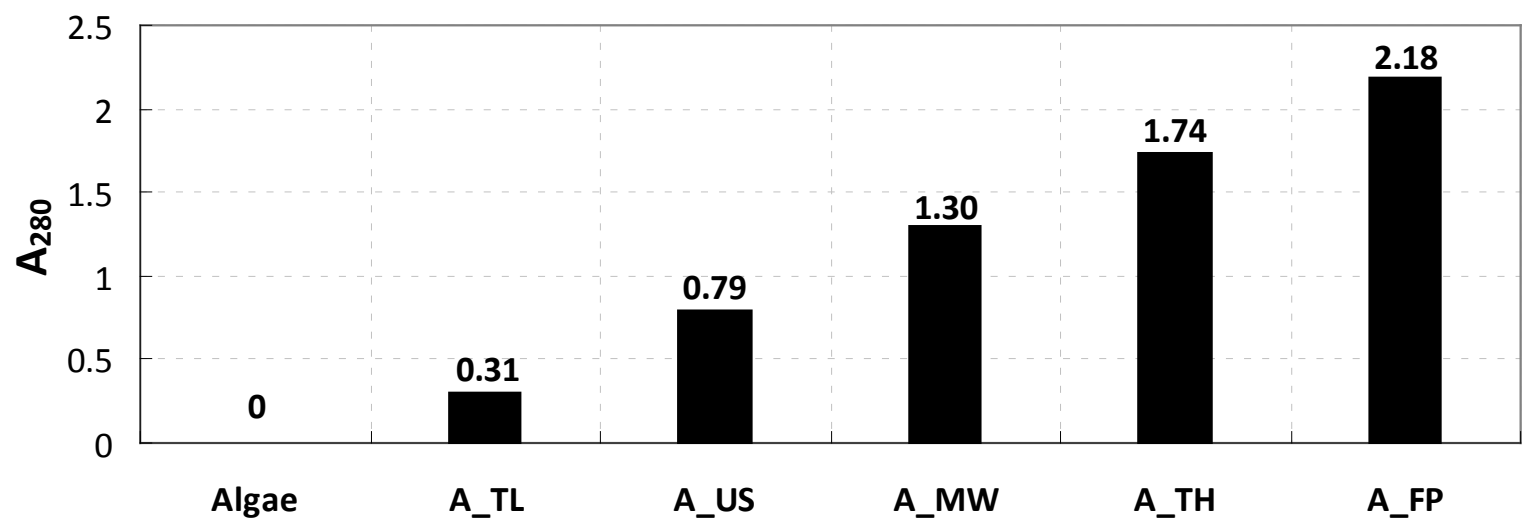

Fig. 1. Absorption at $280 \mathrm{~nm}\left(A_{280}\right)$ of disrupted cell suspensions compared to the untreated sample $($ Algae $) .\left(A \_T L\right)=$ low temperature, $\left(A \_U S\right)=$ ultrasonic, $\left(A \_M W\right)=$ microwave, $\left(A \_T H\right)=$ high temperature and $\left(A \_F P\right)=$ French press.

VS were determined before and after anaerobic digestion. The VS degradation was calculated for the substrate (Figure 2). For all disrupted samples the VS degradation was higher than for the untreated sample (25.2\%). High temperature (53.8\%), French press $(54.5 \%)$ and microwave (58.7\%) were in the same range between 50 and $60 \%$. Lower degradation rates were determined for ultrasonic (41.4\%) and the frozen sample (35.4\%).

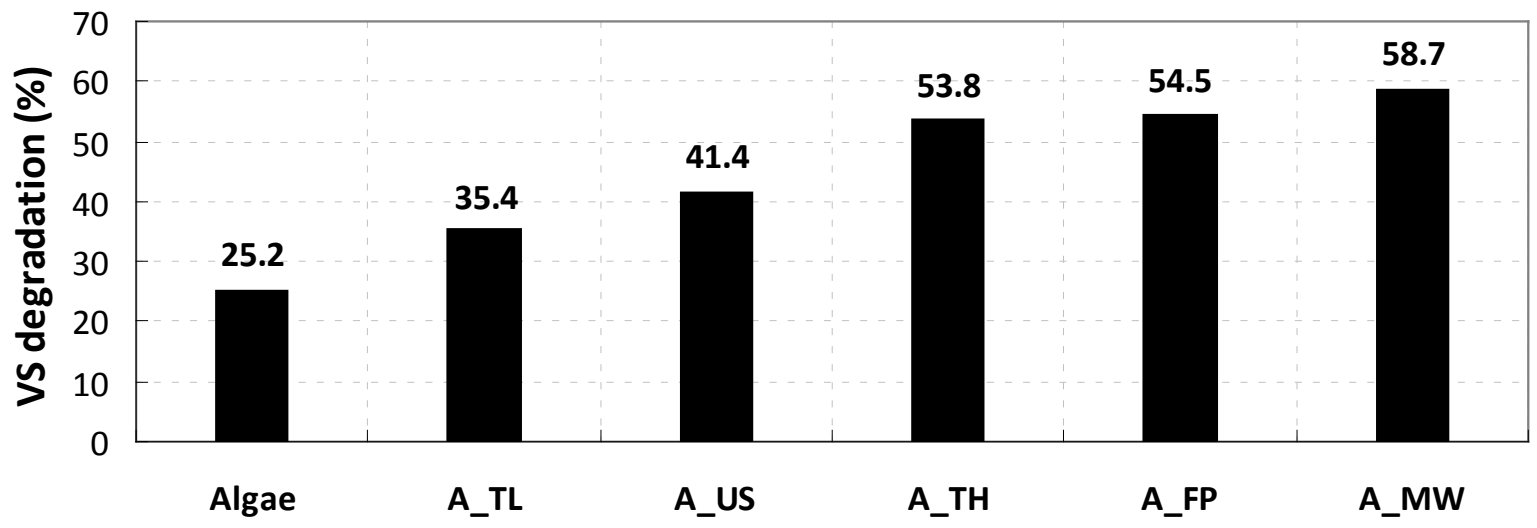

Fig. 2. Volatile solid (VS) degradation of disrupted samples compared to the untreated sample $($ Algae $) .\left(A \_T L\right)=$ low temperature, $\left(A \_U S\right)=$ ultrasonic, $\left(A \_M W\right)=$ microwave, $\left(A \_T H\right)=$ high temperature and $\left(A \_F P\right)=$ French press.

To compare the digestion progression of the different samples the determined biogas volume was calculated by regression analysis (Eq. (1)). The biogas produced by the inoculum was 
deducted (Figure 3). High temperature (A_TH) and microwave (A_MW) disruption showed the highest biogas volume and exhibited a saturation curve, where biogas volume of A_TH (2150 mL) was above A_MW (1900 mL). Biogas volume of the French press sample (A_FP; $1800 \mathrm{~mL}$ ) was highest during the first 13 days and dropped then below A_TH and A_MW. The untreated sample (Algae; $1265 \mathrm{~mL}$ ) exhibited a plateau after ten days and reached saturation after 30 days. The progression of produced biogas volume for ultrasonic (A_US) and the frozen sample (A_TL) are similar to the untreated sample. Evolved biogas was for A_US $(1080 \mathrm{~mL})$ at the beginning higher and at the end below the Algae, whereas the produced biogas volume for A_TL $(920 \mathrm{~mL})$ was below the untreated sample for the whole experiment.

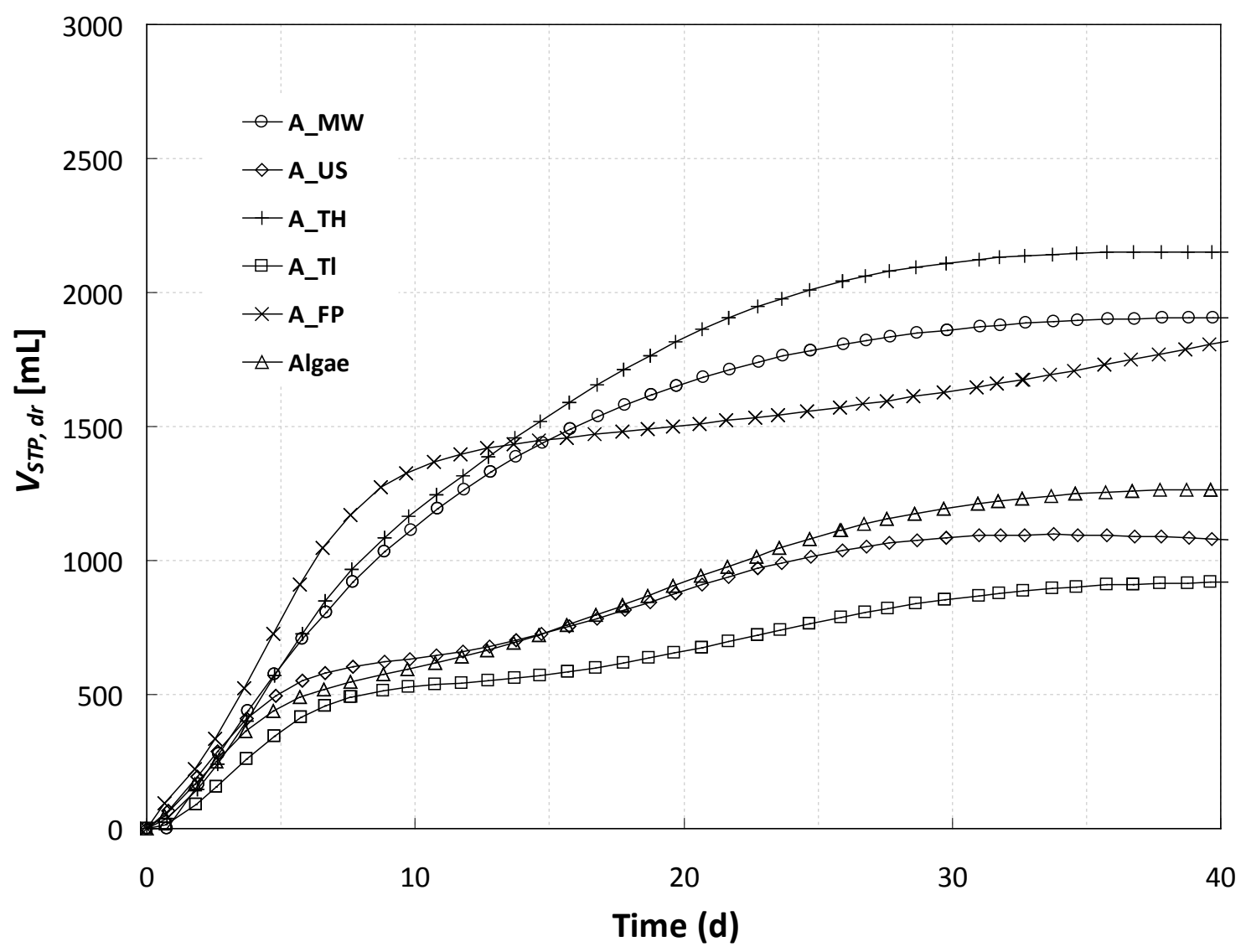

Fig. 3. Biogas production. Biogas volume is indicated in $m L$ as dry gas under standard temperature and pressure conditions (STP, dr). High temperature (A_TH), microwave ( $\left.A_{-} M W\right)$ and French press (A_FP) show different progression and higher biogas volume compared to the untreated sample (Algae). The biogas production progression for ultrasonic (A_US) and the frozen sample (A_TL) is similar, the biogas volume lower as in the untreated sample. VS content was from 3.7 to $3.9 \mathrm{~g}$.

Specific biogas production referred to the added amount of VS was determined for comparability (Figure 4). Compared to the untreated sample (Algae; $347 \mathrm{~mL}_{S T P, d r} / \mathrm{g}$ VS) frozen (A_TL; $233 \mathrm{~mL}_{S T P, d r} / \mathrm{g} \mathrm{VS}$ ) and ultrasonic (A_US; $247 \mathrm{~mL}_{S T P, d r} / \mathrm{g} \mathrm{VS}$ ) samples showed lower specific biogas production. In French press (A_FP; $460 \mathrm{~mL}_{S T P, d r} / \mathrm{g} \mathrm{VS}$ ), microwave (A_MW; $487 \mathrm{~mL} \mathrm{LTP}, d r_{\mathrm{g}} / \mathrm{g}$ VS) and high temperature (A_TH; $549 \mathrm{~mL}$ STP,dr $/ \mathrm{g}$ VS) treated samples the biogas yield was higher than in untreated samples. Due to similar VS content order of specific biogas production is comparable to produced biogas volume stated above. 


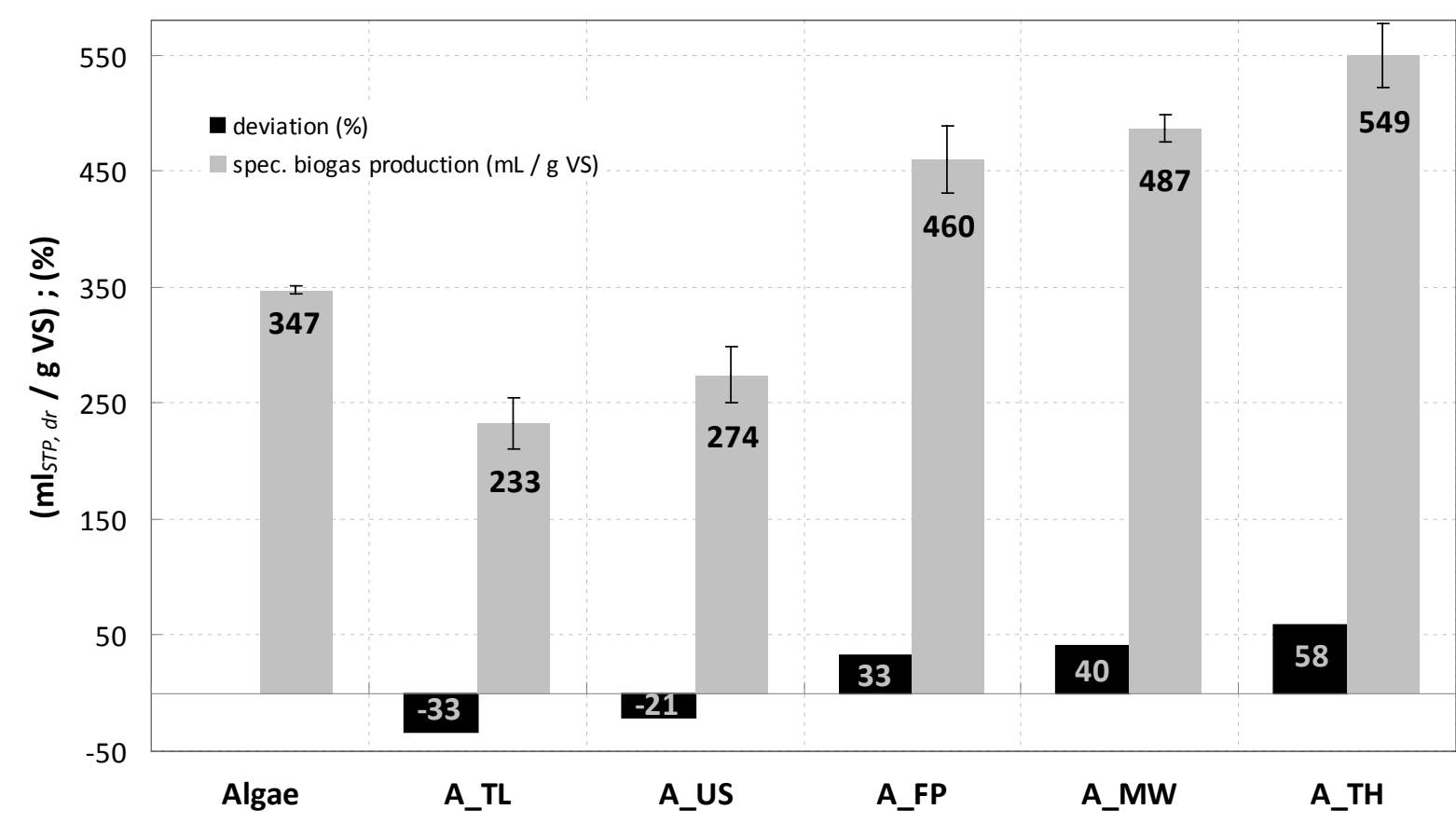

Fig. 4. Specific biogas production of disrupted samples in comparison to the untreated sample (Algae). The freezing (A_TL) and ultrasonic treatment (A_US) showed lower specific biogas production. Increasing biogas yields were determined for French press (A_FP), microwave (A_MW) and high temperature (A_TH) samples. In addition deviation of specific biogas production from the untreated sample was stated.

\section{Discussion and conclusions}

The results indicate that effectively cell wall degradation is a limiting factor in anaerobic mono-digestion processes of N.salina biomass. The validation of cell disruption efficiency shows enhancement for all disruption techniques. Higher VS degradation and lower specific biogas production for the frozen (A_TL) and the ultrasonic (A_US) treated samples are a sign for loss of volatile organic material during cell disruption. Gas bubbles due to cavitation in ultrasonic samples were not yet examined. Microwave (A_MW) and French press (A_FP) samples showed higher VS degradation than high temperature samples (A_TH) with less specific biogas production. Organic material must have been lost in these processes, too.

The appropriated cell disruption techniques showed different efficiency and effects on anaerobic digestion. Thermal pretreatment exhibited the best results as indicated by Chen and Oswald in previous studies, where methane formation efficiency was improved by up to 33\% [11]. Ultrasonic treatment improved substrate solubility, whereas a negative effect on specific biogas production was observed as indicated by Samson and LeDuy for Spirulina maxima algal biomass [12]. The effect was explained by changes in the chemical composition of the culture media due to cell disruption. VS degradation was differently to the data obtained in this work below the untreated sample. Sonification and high pressure homogenization (French press) are standard methods for disruption of algal and bacterial cells in protein purification. Microwave irradiation gains significance in lipid extraction from algae for biofuel production $[13,16]$. For French press and microwave no comparative data of algal fermentation after cell disruption is available.

In this work one major limiting factor for N.salina mono-digestion was revealed: the resistance of the algal cell wall against enzymatic hydrolysis. Mussgnug et al. showed that 
without pretreatment the accessibility to cell disintegration is a Major factor for efficiency of fermentative biogas production [17]. Easy degradable microalgae were found to have no cell wall (Dunaliella salina) or a protein-based cell wall without cellulose or hemicellulose (Chlamydomonas reinhardtii). Specific biogas production of untreated D.salina (505 $\mathrm{mL}_{S T P, d r} / \mathrm{g}$ VS) and C.reinhardtii biomass ( $587 \mathrm{~mL}_{S T P, d r} / \mathrm{g} \mathrm{VS}$ ) was in the range of high temperature samples ( $549 \mathrm{~mL}_{S T P, d r} / \mathrm{g}$ VS) with highest specific biogas production after pretreatment in this work. The cell degradation was $100 \%$ for D.salina and $70 \%$ for C.reinhardtii. After pretreatment of N.salina a maximum of about 60\% (A_MW) degraded VS were determined. Consequently, N.salina cell wall is resistant against enzymatic hydrolysis and degradability was improved by physical pretreatment. Whether the cell wall is partly resistant against the different disruption techniques or other limitations like low $\mathrm{C} / \mathrm{N}$ ratio or ammonia-inhibition affect the low degradability after pretreatment, is ambiguous. A control with $100 \%$ cell disintegration was not conducted in this work.

The potential of microalgae for biogas production is depending on the selected strain [17]. Besides the cell disintegration due to cell wall structure, factors like growth kinetics, biochemical composition or biomass yield are important selective parameters for evaluation. Combined biorefinery concepts can be a possible solution to reduce the influence of cell wall hydrolysis. Anaerobic digestion of pretreated microalgae after lipid extraction for biodiesel production can be the key process to make microalgae sustainable as a source for biofuels by nutrition and energy recovery [6].

In further studies the rated ranges with positive effects have to be investigated for the different disruption approaches. Energy balances with regard to commercial applications have to be examined.

\section{Acknowledgements}

We thank RWE Innogy GmbH for supporting the project and Phytolutions Ltd. for providing the algal biomass. This work was partly supported with a grant by the Graduate School of Energy Efficient Production and Logistics.

\section{References}

[1] Y. Chisti, Biodiesel from microalgae, Biotechnology Advances 25, 2007, pp. 294-306.

[2] A. S. van Carlsson, J. B. Beilen, R. Möller, D. Clayton, Micro- and macroalgae utility for industrial applications. Outputs from the EPOBIO project. D. Bowles. York, UK, 2007.

[3] V. Patil, K. Tran, H. R. Giselrød, Towards sustainable production of biofuels from microalgae, International Journal of Molecular Sciences 9, 2008, pp. 1188-1195.

[4] L. Rodolfi, G. Chini Zittelli, N. Bassi, G. Padovani, N. Biondi, G. Bonini, M. R. Tredici, Microalgae for oil: Strain selection, induction of lipid synthesis and outdoor mass cultivation in a low-cost photobioreactor, Biotechnology and Bioengineering 102, 2009, pp. 100-112.

[5] P. Weiland, Biogas production: current state and perspectives, Applied Microbiology and Biotechnology 85, 2010, pp. 849-860.

[6] B. Sialve, N. Bernet, O. Bernard, Anaerobic digestion of microalgae as a necessary step to make microalgal biodiesel sustainable, Biotechnology advances 27, 2007, pp. 409416. 
[7] S. Derenne, C. Largeau, C. Berkaloff, B. Rousseau, C. Wilhelm, P. G. Hatcher, Nonhydrolysable macromolecular constituents from outer walls of Chlorella fusca and Nanochlorum eucaryotum, Phytochemistry 31, 1992, pp. 1923-1929.

[8] F. Gelin, I. Boogers, A. A. M. Noordeloos, J. S. S. Damste, R. Riegman, J. W. de Leeuw, Resistant biomacromolecules in marine microalgae of the classes Eustigmatophyceae and Chlorophyceae: Geochemical implications, Organic Geochemistry 26, 1997, pp. 659675.

[9] DIN EN 12880, Bestimmung des Trockenrückstandes und des Wassergehalts, 2001.

[10] DIN EN 12879, Bestimmung des Glühverlustes der Trockenmasse, 2000.

[11] P. H. Chen, W. J. Oswald, Thermochemical treatment for algal fermentation, Environment International 24, 1998, pp. 889-897.

[12] R. Samson, A. Leduy, Influence of mechanical and thermochemical pretreatments on anaerobic digestion of Spirulina maxima algal biomass, Biotechnology Letters 5, 1983, pp. 671-676.

[13] J. Lee, C. Yoo, S. Jun, C. Ahn, H. Oh, Comparison of several methods for effective lipid extraction from microalgae, Bioresource Technology 101, 2010, pp. 75-77.

[14] K. Cormann, M. Ikeuchi, M. Rögner, M. Nowaczyk, R. Stoll, Sequence-specific ${ }^{1} \mathrm{H},{ }^{13} \mathrm{C}$, and ${ }^{15} \mathrm{~N}$ backbone assignment of Psb27 from Synechocystis PCC 6803, Biomolecular NMR Assignments 3, 2009, pp. 247-249.

[15] VDI 4630, Vergärung organischer Stoffe, 2005.

[16] S. Balasubramanian, J. D. Allen, A. Kanitkar, D. Boldor, Oil extraction from Scenedesmus obliquus using a continuous microwave system - design, optimization, and quality characterization, Bioresource Technology 102 , 2011, pp. 3396-3403.

[17] J. H. Mussgnug, V. Klassen, A. Schlüter, O. Kruse, Microalgae as substrates for fermentative biogas production in a combined biorefinery concept, Journal of Biotechnology 150, 2010, pp. 51-56 